\title{
RECENT TRENDS IN COMPUTER ADIED FIXTURE DESIGN: REVIEW ON APPROACHES
}

\author{
Harshita S. Umale ${ }^{1}$, Nilesh H. Khandare ${ }^{2}$, Rajkumar D. Palhade ${ }^{3}$

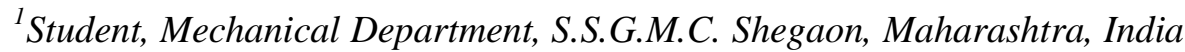 \\ ${ }^{2}$ Assistant Professor, Mechanical Department, S.S.G.M.C. Shegaon, Maharashtra, India \\ ${ }^{3}$ Associate Professor, Mechanical Department, S.S.G.M.C. Shegaon, Maharashtra, India
}

\begin{abstract}
The smart consumer demands for quality product along with the variety, so to cope up with this demand we need a smart market too, having quality and variety as its key factors. For effective respond to this demand we need efficient flexible manufacturing methods, which will let us to gain fast product development. According to studies, fixtures play a very vital role in product manufacturing quality, productivity and cost of the product. Hence designing a fixture according to requirements of the process is very crucial work. This paper is a review of literature survey about Computer Adied Fixture Design and its approaches. It includes the basic importance of fixture and appropriate fixturing techniques, also the design consideration and requirements that are the non negligible factor while fixture designing. It deals with how proper fixture and fixturing techniques are directly proportional to the problem free machining.
\end{abstract}

Keywords: Computer A Died Fixture Design, Design Considerations, Unit Design, Fixture Verification, Collision Detection, Error Analysis.

\section{INTRODUCTION}

Fixture in an instrument used to hold the workpiece at one place firmly and stable for maintaining the accuracy while machining, assembly, inspection and other operations are been carried out on the work piece. A fixture is composed of locators and clamps. Locator is a device that works for specifying the location and orientation of a workpiece, on the other hand clamps helps in holding the work piece by exerting clamping forces so that the workpiece is pressed tightly against locators.

Study says, when the workpiece is fixed on the particular fixture for performance of any operation, then the precision level of the operation is directly proportional to the efficiency of the fixturing method. It is clear that particular fixture should be selected according to the properties of the work piece and the nature of operation going to be performed on it.

Following are the design considerations for fixture:

- Type and capacity of machine.

- Size, shape, weight, material of the component.

- Method of loading and unloading.

- Method of clamping.

- Provision for power operated devices if needed.

- Problem of vibration.

- Safety aspects.

- Provision for fixing a body on a table.

- Method of manufacturing

- Simplifying the design in order to economise the cost.
In earlier days the fixture design methods were based on the designer experience, his knowledge and conclusion about the workpiece, and was tested on trial and error basis, also this was more time consuming.

The market is speedily ascendant and vastly competitive, which forces and also encourages the manufacturing sector for more and more attention on the improved quality and accuracy of the product. Fixture plays a very vital role in this case, and hence we need a very precise design of our fixture so that it can perfectly do its job of holding the workpiece in less time.

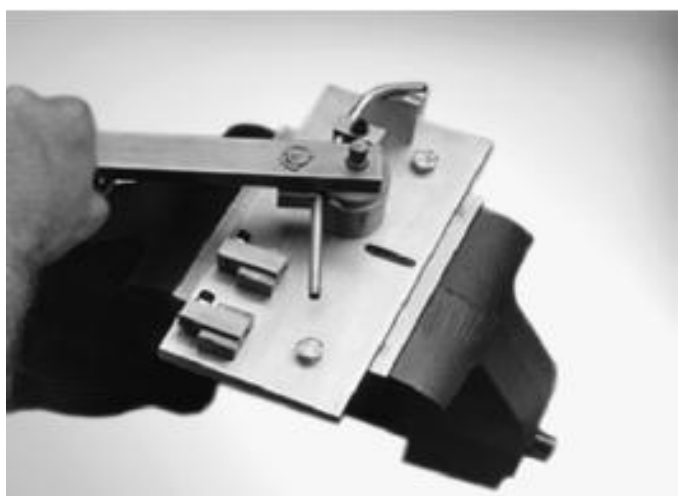

Fig 1: A dedicated tube bending fixture [10]

\section{COMPUTER ADIED FIXTURE DESIGN:}

Unlike in every field computer is also been used for designing a fixture in the form of Computer Adied Fixture Design. This part focuses on recent CAFD research work, concentrating on the procedure that is based on the four major steps for designing a fixture. Fig no 1. 


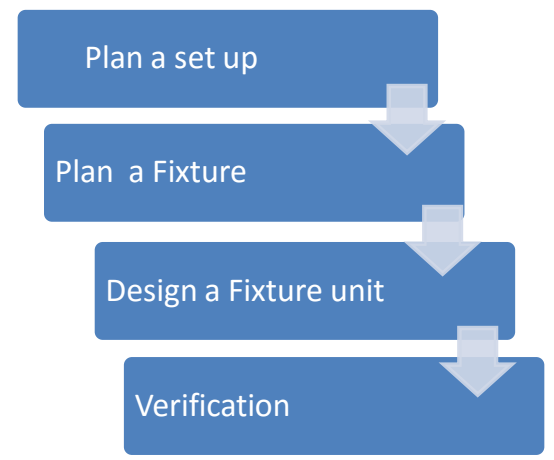

Fig 2: Steps in CAFD.

\subsection{Four Main Phases In Computer A died}

\section{Fixture Design Process Are}

There are main four phases if computer adied fixture design, which successively works in this sequence to get a fruitful output in form of desired fixture.

\subsubsection{Set up planning}

Setup planning deals with the different arrangement necessary to carry out manufacturing operations, and the work to be done at each setup. A setup mainly works on grouping possible number of processes that are going to be done on the workpiece by an indivisual setup with minimum or no changes in the orientation of workpiece. For example machining processes like, pocketing, drilling, making hole etc are processes in which material removal takes place, combining all this process to be done in single setup is the main task in setup planning.[1]

\subsubsection{Fixture planning}

In fixture planning, identification of the exact location of the locating and clamping points on the workpiece, also specifying the area of workpiece on which the locators and clamps are needed to be act. The arrangement and location of the locating points should be in such a way that the workpiece should remain properly constraint during the performance of machining or manufacturing processes on it. Various factors like tolerance, affordability, collision prevention etc. are taken under consideration during fixture planning.[1]

\subsubsection{Fixture unit design}

Designing an unit includes both the therotical and thorough information of the clamps and locators of a fixture, which are fixed on the base plate. This part includes locating devices or clamping devices which acts as a mediator between work piece and a structural support to which they are attached hence gets connected with the base plate. The role of structural support is to provide rigidity to the locating and clamping unit so that they can endure various forces that are going to act on them while machining, and keep the workpiece undisturbed at the desired place. [1]

Frequently traditional geometric based designing tools are used in manufacturing, for example, CAD approaches, like Pro/Engineer and Unigraphics are frequently used as design implements for designing fixture. [2]

\subsubsection{Verification}

During verification it is checked that whether designed made by us satisfactorily fulfills all ourdesired requirements or not. Number of design parameters are taken under consideration like cost of fixture, weight of fixture, assembly time required, both the loading and unloading time for the workpiece on the fixture etc. There are some fixturing requirements which are verified in this stage.

Table -1

\begin{tabular}{|c|c|}
\hline $\begin{array}{l}\text { Generic } \\
\text { requirements }\end{array}$ & Conceptual requirements instances \\
\hline Physical & $\begin{array}{l}\text { - The fixturing device should be } \\
\text { strong and sturdy enough to hold the } \\
\text { workpieces. } \\
\text { - The fixture must not create any } \\
\text { obstacle during the machining of the } \\
\text { workpiece. }\end{array}$ \\
\hline Endurance & $\begin{array}{l}\text { - Endurances at locators of fixturing } \\
\text { device must be enough to fulfil the } \\
\text { component design endurances. }\end{array}$ \\
\hline Constraints & $\begin{array}{l}\text { - Mobility of the workpiece should be } \\
\text { restricted by the Fixture. The } \\
\text { movement of workpiece should be } \\
\text { strictly avoided. } \\
\text { - It should be checked that no damage } \\
\text { or deformation should be occurred in } \\
\text { both workpiece and fixture. Incase if } \\
\text { it occurs design is needed to } \\
\text { rechecked. }\end{array}$ \\
\hline Affordability & $\begin{array}{l}\text { - The design fixture should be cost } \\
\text { effective. The cost should be } \\
\text { estimated considering the purpose of } \\
\text { our fixture. } \\
\text { - The time for assembling the fixture } \\
\text { should be less. } \\
\text { - Also the loading and unloading of } \\
\text { the workpiece on the fixture should } \\
\text { be convenient }\end{array}$ \\
\hline $\begin{array}{l}\text { Collision } \\
\text { prevention }\end{array}$ & $\begin{array}{l}\text { - The fixture should not create any } \\
\text { kind of hurdle in between the } \\
\text { workpiece and tool. } \\
\text { - Care should be taken to avoid 1)tool- } \\
\text { fixture collision, and 2)fixture- } \\
\text { fixture collision. }\end{array}$ \\
\hline Usability & $\begin{array}{l}\text { - Fixture should provide ease in } \\
\text { machining operation, by guiding the } \\
\text { tool according to the workpiece } \\
\text { shape required. } \\
\text { - Fixture should be of proportionate } \\
\text { weight. } \\
\text { - Fixture should not be a reason for } \\
\text { any damage to the workpiece. } \\
\text { - Fixture should be designed in such a } \\
\text { way that there should not be any } \\
\text { scope of miss aligned workpiece } \\
\text { arrangement. }\end{array}$ \\
\hline Safety & $\begin{array}{l}\text { - Fixture should be safe for the } \\
\text { worker, who is going to work on it. }\end{array}$ \\
\hline
\end{tabular}




\subsubsection{Verification of physical requirements}

While designing a fixture the very first point needed to be considered is the purpose of the fixture, according to that the design should be proposed. The shape and size of the workpiece is needed to be studied, and then a fixture should be designed which will be able to bear the load of the workpiece, the forces acting on the workpiece while machining is performed. Fixture must permit the requirement of the workpiece feature to be machined.

\subsubsection{Verification of constraints}

The main purpose of the fixture is to place the workpiece at one place, to strictly restrict its movement. While designing the fixture it is necessary that it should fulfill this requirement. While the machining is done on the workpiece held in the fixture, many forces acts on both the workpiece and fixture. So while designing we should ensure that this forces must not affect the work piece of fixture. No damage or dents should occur on them. The proper location of the clamps is also an important factor in this case.

\subsubsection{Verification of affordability and usability of fixture}

Considering the cost of the fixture is a important, but is slightly neglected. The cost of fixture should be affordable to the customer.Time requirement for assembling the fixture should be less, so that it will save time. Also the loading and unloading of the workpiece on the fixture should be convenient. Our fixture design should not cause change in properties or parameters of the workpiece.

\subsubsection{Verification of Collision requirement}

There should be no interference of fixture during the machining process. In this approach we detect that a) is our fixture causing any kind of hurdle in the tool path while machining, b) is there any collision between workpiece and fixture, c) does the fixture parts collides with each other. If any of the above case occurs, it becomes necessary to check the design again. Collision may also occur while clamping the work piece of the fixture, so it essential to work on collision free clamping.

Number of recent CAD approaches are able to execute fixture-fixture impact identification, whose examination is done by geometric constraint for finding a solution to fortify that collision of fixture components is restricted apart from their allotted connection spots [13].

Investigating the fixture and tool path collision is a critical work. Kumar et al. [5] used a cutter swept volume method, in this method extrusion operation is done on the cross sectional area of cutting tool to achieve a swept volume. A static interference check is then done to make check if this swept volume befall on any part of the fixture and, if impact takes place. Roy and Liao [6] didn't just checks area of impact but additionally gave shortcut methods to maintain foundation and clamp spots in such a way that impact occurrence will be avoided, in short that the workpiece won't get fixed until it is properly aligned on the fixture. It will also increase the safety.

\subsubsection{Deformation and error analysis of fixture- workpiece system}

A flaws at certain location of the part to be operated are caused due to failure of locating spot, geometric flaws in surface touched locating devices, and the datum geometric failure of part to be operated, due to which in a machined feature linked form flaw is occurred. According to ( M.Y. Wang) the chief three causes for error due to position of fixture are: (a) Main cause of the fixel flaws of the locating device is difference in the location of a locator. (b) Second cause is difference in the geometric structure of the locating device, like profile endurance defined for a circular locating device. When process is carried out, the fixel error is also seen due to the physical distortion in the locating device for example wearing and tearing of the locator. (c) The next cause is linked to geometric differences which is present in the physical datum element of the part. [2]

\section{CONCLUSION}

This paper focuses on the design considerations and vital requirements of fixture designing. It gives review of CAFD approaches in the form of stages used in the computerized designing process. It is earlier known that improvement in computer adied fixture design is beneficial in aspects like it is very accurate, highly efficient, reduced arrangement time of the setup and loading and unloading time, and minimized cost. Computer adied fixture design system is strongly expected to be more robust, dynamic, accurate and safe than a manually designed fixture. It provided $\mathrm{u}$ an efficient fixture that helps in increasing the quality of the product, we get an precise and well finished product in less time. CAFD focuses on the vital requirements of the fixturing, on getting the fixture design ready, verification is done and it is checked if we have satisfied them.

Fixture design is a part of manufacturing process, and it should follow to the main purpose of workpiece manufacturing requirements which are linked with production resources, cost of equipment, and machining operations, etc. Hence, it is essential to include the fixture design task into the complete manufacturing process to accomplish the best fixture design as a solution.

It can be clearly seen that nearly all the article is highlighting area of fixturing techniques used in manufacturing area. Other than the conventional machining area, there are vast application of fixturing devices in various trades of manufacturing firms. We have a chance for further exploration in designing a fixture with the help of computer in this area. According to table- 1 there are some essential and required design considerstions.

Moreover, drift in flexible production techniques and specialised small manufacturing firms will recommend more wide observasions, deep study and analysis on the utility and suitability of computer adied fixtures and assigned fixturing devices. 


\section{ACKNOWLEDGEMENT}

The writer is thankful to all the referees, for there useful research which substantially helped in improvement of the article. We are happy to express our gratitude from the Mechanical Dept. of Shree Sant Gajanan Maharaj College of Engg Shegaon, Maharashtra, India.

\section{REFERENCES}

[1]. Iain Boyle, YimingRong, DavidC.Brown. A review and analysis of current computer-aided fixture design approaches. Robotics and Computer-Integrated Manufacturing 27(2011) 1-12.

[2]. Hui Wanga, Yiming (Kevin) Rong, Hua Li, Price Shaun Computer aided fixture design: Recent research and trends. Computer-Aided Design 42 (2010) 10851094.

[3]. Saigopal Nelaturi, Arvind Rangarajan, Christian Fritz, Tolga Kurtoglu Automated fixture configuration for rapid manufacturing planning. Computer-Aided Design 46 (2014) 160-169.

[4]. Giovanni Moronia, Stefano Petroa, Wilma Polinib "Robust design of fixture configuration" Procedia CIRP 21 (2014) 189-194.

[5]. Kumar AS, Subramaniam V, Teck TB. An automated design and assembly of interference-free modular setup. Comput Aided Des 2000;32:583-96.

[6]. Roy U, Liao J. Application of a blackboard framework to a cooperative fixture design system. Comput Ind 1998;37:67-81.

[7]. Kang Y. Computer-aided fixture design verification. Ph.D. dissertation. USA: Worcester Polytechnic Institute; 2001.

[8]. Kim I-H, Oh J-S, Cho K-K. Computer aided setup planning for machining processes. Comput Ind Eng 1996;31(3/4):613-7.

[9]. Nnaji BO, Alladin S, Lyu P. A framework for a rulebased expert fixturing system for face milling planar surfaces on a CAD system using flexible fixtures. J Manuf Syst 1988;7(3):193-207.

[10]. http://www.wintonmachine.com/.

[11]. Cecil J. Computer-aided fixture design-a review and future trends. International

[12]. Journal of Advanced Manufacturing Technology 2001;18(11):790-3.

[13]. Nee AYC, Whybrew K, Senthil Kumar A. Advanced fixture design for fms.

[14]. London: Springer-Verlag; 1995.

[15]. G. Peng, G. Wang, W. Liu, H. Yu, A desktop virtual reality-based interactive modular fixture configuration design system, Comput Aided Des, 2009, doi: 10.1016/j.cad.2009.02.003. 